\title{
Emerging Promise of Nanoparticle-Based Treatment for Parkinson's disease
}

\author{
Md. Mominur Rahman ${ }^{1, *}$ (D), Kazi Sayma Ferdous ${ }^{1}$, Muniruddin Ahmed ${ }^{1}$ \\ 1 Department of Pharmacy, Faculty of Allied Health Sciences, Daffodil International University, Dhaka-1207, Bangladesh \\ * Correspondence: momin10mar@gmail.com;
}

Scopus Author ID 55457961000

Received: 10.05.2020; Revised: 3.06.2020; Accepted: 4.06.2020; Published: 7.06.2020

\begin{abstract}
Neurodegenerative disorders are consequences of the deterioration of cells and tissues with a mature undesirable way of life. The degenerative disease like Parkinson's disease (PD) influences Central nervous systems (CNS) and cardiovascular systems. In this study, we show Parkinson's disease combined with rising nanoparticles, draw hopeful methodologies for improving medication transport to the scattered CNS, and examine their suggestions for clinical practice. A search strategy was designed in order to identify articles published in the high ranking journals. All the search results from the prominent databases, namely Scopus, Springer, PubMed, Cochrane, and ScienceDirect, were collected, and all possible duplicates were discarded. The worse condition must be overcome by traditional treatment systems. Nanotechnology and nanoparticles based methodology medical transport systems could reverse the treatment of Parkinson's disease. Dopamine consumption in the striatum is the sign of PD and its creation forms. Still, the pathophysiology of the parkinsonian side effects and especially parkinsonian trembles are under discussion. Parkinson's disease alarms genuine anxiety because of its consequences for the personal satisfaction of patients and its burden to social prescriptions and treatments that have risen for the management.
\end{abstract}

Keywords: Parkinson's disease; Central nervous system; Nanoparticles; Dopamine; Cardiovascular systems.

(C) 2020 by the authors. This article is an open-access article distributed under the terms and conditions of the Creative Commons Attribution (CC BY) license (https://creativecommons.org/licenses/by/4.0/).

\section{Introduction}

Parkinson's disease (PD), Multiple sclerosis (MS), Amyotrophic lateral sclerosis (ALS), and Alzheimer's disease (AD) are examples of neurodegenerative disorder and happened because of the combination of inherited and ecological influences of maturing [1-3]. At present, $\mathrm{PD}$ is in the second position after $\mathrm{AD}$, among other well-known neurodegenerative diseases, and contains a trademark in motor and non-motor indications [4]. All-inclusive, the pervasiveness of PD has been seen as near $0.3 \%$ of the total people with an unrefined occurrence rate of 4.5-19 for every 100,000 people every year. The WHO figured the quantity of years loss of sound lifespan, because of PD to mean 1,617,000 universally in 2005 and predicted it to increment to $2,015,000$ years by $2030[5,6]$. The situation implies that an everincreasing number of people would make lives with inabilities because of Parkinson's disease. In established nations like the USA, the national financial weight of Parkinson's disease was further than USD 14.4 billion out of 2010 (around USD 22,800 for each victim) [7]. In innovative nations such as India, PD patients were seen to use almost $16 \%$ to $41.7 \%$ of the normal Indian gross national pay as immediate expenses in PD [8]. PD's administration has a few restrictions at present. The experimental finding of PD begins to acclaimed nervous system 
specialists like Parkinson and Charcot, who saw the similarity of a few motor highlights including bradykinesia, rigidity, and tremor was normal for PD [9, 10]. After two centuries, the concern with the medical determination of Parkinson's disease in the present day is that it neglects to separate it from the numerous types of Parkinsonism [11-15]. Likewise, it helps master healthcare providers for the evaluation of these abstract highlights of the disease. In this way, there is a requirement for better biomarkers that can accommodate a target evaluation of the non-appearance of PD. Standard treatment involves treatment utilizing dopaminergic and non-dopaminergic to advance medical indications related to sickness movement, victim's consideration, and personal satisfaction. But, short half-lives, treatment disadvantages along with reactions like levodopa (L-3,4- dihydroxyphenylalanine or L-DOPA) prompted dyskinesia and can limit the long-distance treatment capacity. Further, treatment is forced by the immediacy of the blood-brain barrier [16-19].

Nanoparticles, developing tools can develop such conditions by presenting novel carrier-based periods that will aim particular arrival of medication load with on-demand and correct release energy, and increased range through modification or by crossing the BBB [2022].

The current study describes the utilization of a nanoparticles-based platform for treatment methods of PD.

\section{Materials and Methods}

Peer review articles were identified using a systematic search of databases. A search strategy was designed in order to identify articles published in the high ranking journals. All the search results from the prominent databases, namely Elsevier, Scopus, Springer, PubMed, Cochrane, and ScienceDirect were collected, and all possible duplicates were discarded.

\section{Results and Discussion}

\subsection{Pathophysiological hallmarks of Parkinson disease.}

Parkinson's disease is a chronic, progressive neurologic disease. The main pathophysiological characteristic of PD is the deterioration of dopaminergic (DA) neurons within the substantia nigra $(\mathrm{SN})$ and subsequent dopamine reduction of the striatum. This neurotransmitter manages the excitatory and inhibitory flow of the basal ganglia [23-25]. At the time of death, it has found that PD patients who are mildly affected lose about $60 \%$ of their DA neurons; this damage causes potential malfunction of the rest of the neurons, defines around $80 \%$ injury of DA in the corpus striatum [26]. As the terminals of DA neurons degenerate, DA uptake decreases in great affinity. This joined with several terminations in DA receptors, permit striatal to proceed to serve, excluding interruption or dynamic recompense at the outset stages of the neurodegenerative method. The remaining DA terminals upturn the amount of transmitter that produced and transported to the extracellular fluid. This seems due to a net increase in the amount of DA released in response to terminal depolarization. The enhanced synthesis, as well as the release of DA, may enhance reactive metabolites, which are made from DA, also spread the development of PD [27].

One more pathologic hallmarks of PD is the Lewy body. It is an eosinophilic and presence determined within neurons. They are usually round in nature, while their shape can be pleomorphic and are in general $5-25 \mu \mathrm{m}$ in diameter. Lewy bodies are universally found in the brain areas and showed the maximum neuron damage in PD, including locus coeruleus, 
$\mathrm{SN}$, the nucleus basalis of Meynert, and dorsal motor nucleus of the vagus. They are similarly detected in the neocortex, diencephalon, spinal cord, and peripheral autonomic ganglia [28].

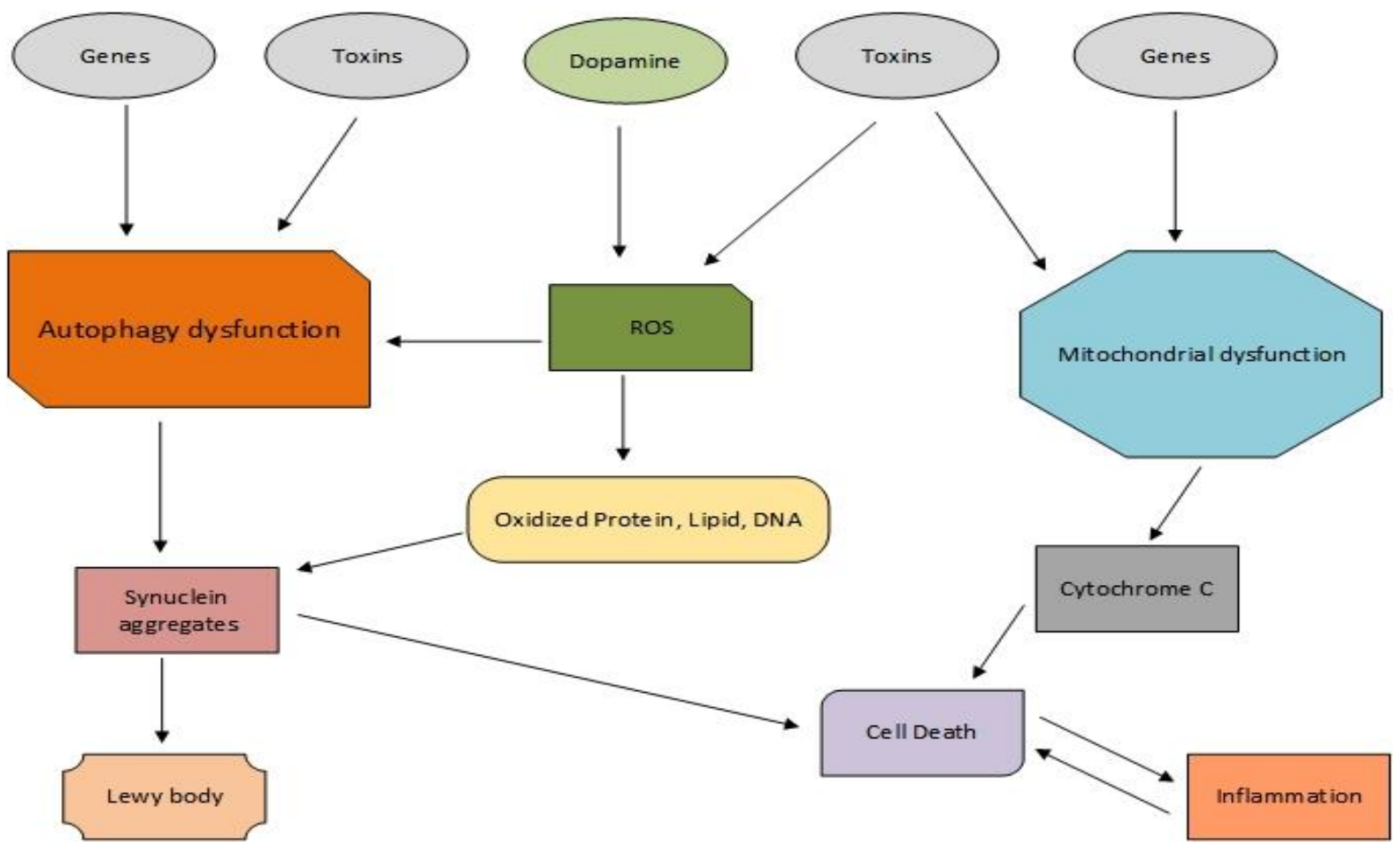

Figure 1. Pathophysiological hallmarks of Parkinson's disease.

On ultra-structural analyses, Lewy bodies contain an electron-dense granular core and a peripheral halo that contains radially oriented filaments of 7 to $8 \mathrm{~nm}$ in width [29]. These filaments look like neurofilaments, and they can be immune stained with antisera to neurofilament proteins including the NF-L, -M, and -H forms [30, 31]. Many big antigenic features of Lewy bodies are the expression of cellular proteins that are convoluted in protein degradation includes ubiquitin [32] and proteasome [33, 34]. Protein accumulation is risked that completed a notable role in PD pathogenesis, and the figure of the proteins in Lewy bodies tends to promote this concept $[35,36]$. Lewy bodies seem to signify the result of fundamental pathology. Evidence proposes these intra-cytoplasmic presences that do not arise harmful to cells and even maybe cytoprotective. The existence of Lewy bodies is compulsory for pathologic validation of clinical analysis of PD. The neurodegenerative process in PD is not only confined to the SNC but also the neuronal injury. Lewy body development can occur in other brain parts $[24,25,37]$ that may consider for both motor and non-motor characteristics of the disease.

\subsection{Nanoparticles and central nervous system.}

Nanoparticles (NPs) are Nano-technological innovations that have been put in medicine for diagnosing, treating, or preventing human diseases. Because the dimensions of NPs are very much comparable to some of the biomolecules like- proteins, DNA, hemoglobin, cell membranes, and viruses [38]. NPs have become a key subject for drug delivery researches as they can deliver a magnificent amount of medication to almost any area of the body by supplying very meticulous and persistent effects therapeutically [39]. At present, no cure is available for PD. As an alternative strategy, nanoparticles are developed as carriers which can be applied for brain drug delivery [40]. NPs are exceptional, adaptable, flexible structures. 
They can be modified to cover some, or all these following attributes: (i) biologic, (ii) nontoxic, (iii) protect medicines from in vivo deterioration, (iv) capacity to bind and carry several loads, (v) manage medicine discharge for an extended duration and mainly (vi) cross the BBB. Control on these characteristics mainly enhances the ability to penetrate BBB [41]. The strategies to deliver NPs into the CNS are: 1. By increasing BBB permeability with noninvasive methods like intranasal drug delivery [42]; 2. Temporary disruption of BBB [43].

Studies have revealed that endocytosis and transcytosis are the leading mechanisms to transmit the NPs. The receptor-intervened, adsorptive-mediated transcytosis mechanisms and seeing the effects in the passive diffusion process, nanoparticles can undertake transcytosis and cross BBB, by also providing patient-oriented therapy [44]. The drug's plasma concentration can help passive transport by enhancing. It causes a superior gradient at BBB, which increases drug quantity entering the CNS, also- the deterioration of NPs. Those extant pro-adsorption characteristics could upturn passive diffusion [45]. The receptor facilitated mechanism is called transcytosis, which mainly found on the reciprocal act of NPs superficial binding agent, as well as an unambiguous receptor in the $\mathrm{BBB}$. The phases for $\mathrm{BBB}$ crossing involve the collaboration of NPs varied by a receptor. Transcytosis across endothelial cells of BBB, the finding of endocytosis carrier, and exocytosis of NPs. Eventually, certain study groups added new functions to the surface of NPs with binding agents upholding their unambiguous linking to receptors on the exterior endothelial cells of the brain. Explicitly, NPs aim transferrin [46] and lipoprotein receptors [47]. PEGylated immune-liposomes can move in the CNS, mediated by an antibody that can link to the transferrin receptor, and move the load into the brain, not even damaging the BBB [48]. Eventually, precincts of receptor-based methods are based on the connection within receptor and binding agents that are found in NPs surfaces, which results in a low rate of exocytosis. Researchers also figured that a greater proportion of NPs are found in capillary endothelial cells more than they are found in CNS parenchyma if compared. Many other receptors have been revealed, but their variance expressions, transport systems, and instruction at $\mathrm{BBB}$ in the unhealthy brain are not yet fully realized. Again, the intonation of drugs surface charge appealed important interest concerning the adsorptive-mediated transcytosis stimulation of neuropharmaceuticals within the BBB [49, 50]. According to a study, authors had also merged some strategies to enhance the brain intake of NPs. The authors configured PEGylated chitosan (CS) NP transplanted (CS-PEG-OX26)/not transplanted with targeting binding agent OX26 (CS-PEG) [51] to enhance blood circulation time employing PEG, go through adsorptive-mediated transcytosis due to the electrostatic coherence between polycationic CS and negatively charged endothelial cells membrane, through receptormediated transcytosis due to the OX-26 mAb selectiveness. Collected outcomes indicated that NPs were often placed in the hippocampus are eligible for crossing the BBB. It was also found that slight intrusive RNA mediated silencing of the P-gp gene that are in control for efflux mechanisms is a usable plan for developing drug supply to the brain [52,53]. Various study groups said that nanosystems that can carry siRNA to the BBB; with the ambition of advance silencing the $\mathrm{P}$-gp protein receptor, and temporarily making the BBB more absorptive for P-gp substrates. For example, (i) Malmo et al. explored the prospective of siRNA-chitosan NPs in silencing P-gp in a BBB model. The outcomes showed that P-gp silencing by chitosan siRNA NPs were able to produce an upgraded transfer and ability of doxorubicin [54]. (ii) Gomes et al. planned a siRNA transporting nanosystem that is directed against P-gp. Here polymeric poly (lactide-co-glycolide) (PLGA) NPs, with proportions of $\sim 115 \mathrm{~nm}$ in size, offered $50 \%$ siRNA connotation adeptness. The NPs surface was altered with a peptide binding to transferrin 
receptor (TfR), along with their affecting skill opposing human brain endothelial cells, was established. The distinguished functional nanosystem was PLGA and PLGA: PLGA-PEGNH2 (95:5), which was revealed to be mild for endothelial cells of the human brain without any striking cytotoxicity [55]. Some parameters are found to expand the efficacy of NPs general circulation, BBB passageway as well as drug distribution. Investigations also found a contrasting link between the NPs size and BBB penetration.

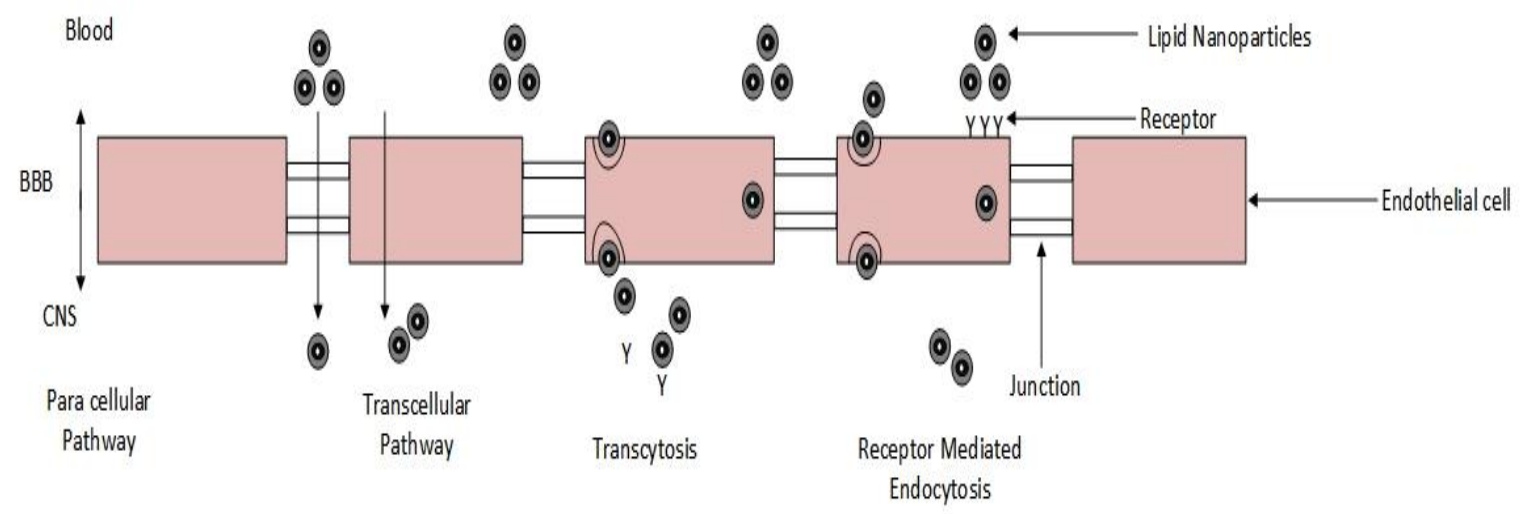

Figure 2. Pathways of nanoparticles passing BBB and aiming the CNS.

More specifically, the NPs size should be between 50-100 nm in diameter. And NPs construction effects on their cellular uptakes and following body distribution.

\subsection{Nanoparticles for Parkinson's disease.}

PD is mainly composed when dopaminergic neurons of the substantia nigra are somehow lost. The motor injury is linked with this drop in dopamine. In the long run, it conducts the way to quivery movement, the unusual steadiness of body activity, and rigidness [56]. Although victims are mostly bought with dopaminergic drugs like levodopa, apomorphine, amantadine, budipine besides these medications also have harsh profit profile fractions. The bioavailability of orally controlled pills depends on some elements of dopamine receptors like gastrointestinal $\mathrm{pH}$ and nutritive protein. No adequate result was displayed by any other administration paths, as nothing may uphold a constant invigoration of dopaminergic drugs. The conversion of a device to nanoscale and a combination of medication for its uninterrupted discharge has turned out to be major defies. That's why nanoparticles are being developed to fight this challenge.

\subsubsection{Polymeric nanoparticles.}

Polymers deal with flexibility, unequaled by other metals or ceramic materials. Therefore non-degradable elements are less engaged, like QDs, fullerenes, carbon nanotubes, metal elements, and silica NPs [57]. Materials used in making NPs include PLGA (poly lacticco-glycolic acid) at altered degrees of composition; polylactic acid; PBCA (poly n-butyl cyanoacrylate); human serum albumin; and a sugar named chitosan, benefitting that, the ionic gelation technique fails to oblige organic solvents. Some problems affiliated with polymeric NP include excess organic solvents, the onset of polymerization, and the construction of lethal monomers $[58,59]$. The usage of polymers used for PD treatment holds the lead of having quite a lot of well-known methods for their improvement and also having widespread evidence on the toxicity of resources. 


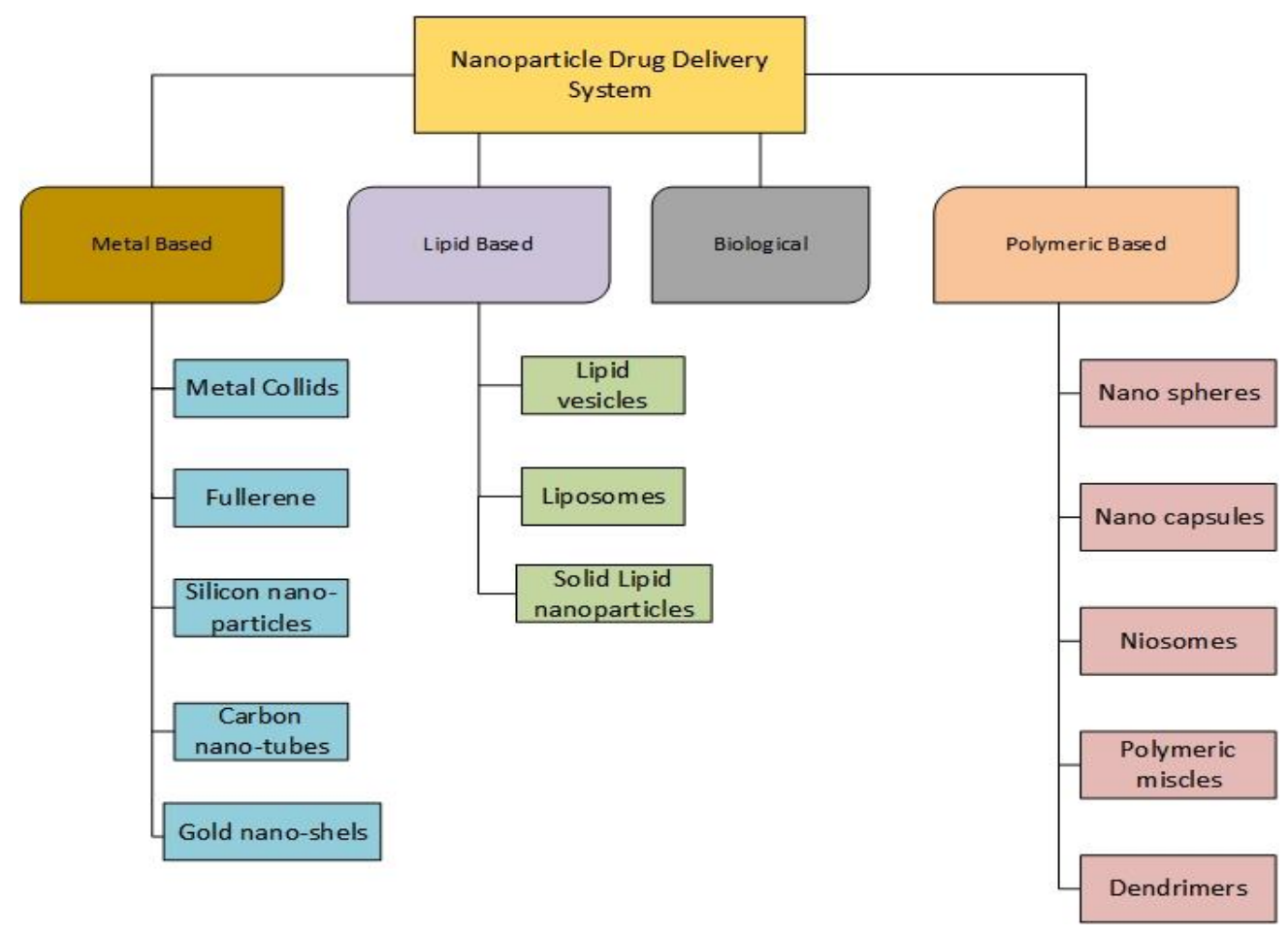

Figure 3. Nanoparticles study of Parkinson's disease

\subsubsection{Solid lipid nanoparticles.}

There is another choice that is arising freshly is the usage of lipids. The phrase lipid omits triglycerides, fatty acids, glycerides, waxes, and steroids. Dispersions organized with lipids apply greatly efficient homogenization methods to yield solid lipid nanoparticles (SLN), a phrase used to describe dispersions of this kind arranged by alternative methods including chemical also. Features of SLN contain controlled release over several weeks, the capacity of vectorizing, with maximum permanency term of three years in certain circumstances [60]. The usage of a great pressure homogenization process permits the inadvertence of organic solvents, whereas enhancing replicating ability [61] as well as the capability of great-range manufacturers [62]. Therefore, SLN contains a striking choice in part as they are physiologically suitable, hence reducing the possible loss instigated by acute or chronic toxicity. Additional significant features omit the existence of polymeric configurations in SLN, their alteration eventually in the direction of additional steady structures, potential dismissal of the drug, and an alteration in the zeta potential of deposited fluid systems. This alteration is fast in short chains of triglyceride than a longer one. This consequence can be minimized by lyophilizing the preparation. Whenever the freeze-drying action is applied, a brief reconstruction time, small or unvaried particle sizes, as well as constant action of the encapsulated drugs, are desired. At the time of sample freezing, there are zones of huge condensation of particulate systems, which includes salts, free surfactant as well as unloaded drug. It possibly can reserve the initial characteristics by engaging a suitable good deal of cryoprotectants, additionally by standardizing the limitations of the process [63]. Certain considerable major factors include icy temperature and speed; measurements and sample attentiveness, nature and denseness of cryoprotection and lyo-protector, denseness and type of stabilizer, heating rate, vacuum pressure, along with the type of suspension. This alteration is slower in the case of lengthy triglyceride chains than smaller ones. The consequence of chain size might be detected in the filling volume of the drugs as lipid templates with a great configuration of diglycerides along with triglycerides specific exposed places whereby the 
medicine might be put in storage. In case of increasing the drug-filling volume, the main feature to be considered is the dissolving ability in the molten lipid, thus equivalent $100 \%$ of the loading capacity. Some additional features like the chemical and physical arrangements which effect on the solid lipid matrix [64-66]. Despite having benefits of SLN preparations, not all particles hold the features mandatory to be combined proficiently into a lipid medium. One substitute that may provide grander capability is the construction of nano-crystals following by using a layer with an appropriate surface-active agent [67]. The usage of lipids for the research of NP for treating PD has been hardly discovered also may bid possible welfares. This includes a substitute to the polymer NP. If a developed drug-loading volume is necessary, then altered chain-length triglycerides, diglycerides, or a combination of both might be preferred. [68]

\subsubsection{Inorganic nanoparticles.}

Inorganic nanoparticles have captivated significant attention for their stimulating physicochemical properties, small and external plasmon comportment [69]. Inorganic nanoparticles like magnetic nanoparticles, gold, chromium, platinum, silica, manganese, palladium, zinc, molybdenum, selenium, cerium oxide, titanium, copper, and silver nanoparticles, nanoshells, nanocages, and bimetallic have been constantly used and improved to establish their usage as therapeutic as well as diagnostic agents. In 1857, the presence of inorganic nanoparticles in solution was primarily renowned by Michael Faraday. In 1908, a calculable description of their shade was specified by Mie [70]. Depending on size and shape, an inorganic nanoparticle display has a variety of functions like catalysis, also sense to optics, antibacterial action, data storage, and cytotoxic possessions [71]. For example, the dimensions and shape of inorganic nanoparticles were thoroughly associated with their bactericidal commotion and cytotoxicity properties. To exact, smaller the metal nuclei, greater the action [72]. The extent of inorganic nanoparticles is generally reliant on temperature, the concentration of metal salt, the chemical precursor level of the reaction medium [73]. Usually, precise nature is adapted by alteration of the production procedures, stabilizers, and reducing mediators [74-78]. Various procedures are observed for the production of nanoparticles. These contain chemical, physical as well as biological ways [79-81]. Nanoscale tools and supramolecular compositions with forms (prisms, spheres, plates, rods, needles, dendrites, or leaves) as well as sub-micrometer dimensions starting from 1 to $100 \mathrm{~nm}$ is a developing region of nano-science along with nanotechnology.

\subsubsection{Gold nanoparticles.}

Gold is another utmost significant plus broadly used noble metals because of its extensive field uses in manufacturing and commercial action. It is the best attractive microelement playing an important part in the field of bio-nanotechnology [82]. Colloidal gold is being used as a medicinal agent for rheumatoid arthritis, alcoholism, tuberculosis, and neoplastic conditions [83]. At present, metallic nanoparticles, mainly gold nanoparticles (AuNPs) have drawn the curiosity of researchers as they have good stability, biocompatibility as well as oxidation resistance. AuNPs offer countless beneficial features for the making of drug delivery systems. Firstly, the fundamental constituents of gold are not cytotoxic [84]. Secondly, its exclusive nano-size dimension delivers a huge superficial region voluntarily open for alteration use for loading target molecules or specific biomarkers for drug delivery systems [85]. It can be applied as a prospective carrier for delivering macromolecules like proteins, DNA, or RNA [86]. It has been found that AuNPs with a diameter $\leq$ of $50 \mathrm{~nm}$ can pass the 
BBB. Furthermore, tumor cells have leaking vasculature, so PEGylated AuNPs conjugated with TNF (tumor necrosis factor) can extravagate over them [87]. Gold nano-rods are found to hold huge prospects to supply RNA to target cells [88].

\subsubsection{Silver nanoparticles.}

Silver nanoparticles (AgNPs) show a fundamental part in the fields of physics, chemistry (catalysis), also healthcare (therapeutics, identification, as well as immune assay) [89-92]. A lot of studies have acknowledged that AgNPs are generally popular for its antimicrobial and anticancer actions [93]. Compared to its ionic form, in nanoparticle silver hold narrow cellular toxicity but does not have bactericidal effectiveness. The superior bactericidal features of AgNPs contribute to the formation of free radicals from the exterior of silver [94]. AgNPs have anti-inflammatory properties as well. In disease management, AgNPs are a common option for their precise collaboration and interruption of the mitochondrial respiratory chain [95]. AgNPs have been confirmed to steady the development of macular degeneration as well as different ocular diseases. The AgNPs prevent the pathway of the growth feature that raises the penetrability of endothelial cells. Completely preventing this absorbency, AgNPs, therefore, steady the advancement of optical degenerative diseases as well as even upsurge visual sharpness in several patients [96].

\subsubsection{Polymer-drug conjugates (PDC) nanoparticles.}

PDC are synthesized by the side-chain embedding of drugs to polymeric bonds, permitting the supply of great quantities of cancer drugs [97]. The presence of the polymer upturns its pharmacokinetic outline as well as raises the solubility of the hydrophobic drug; it decreases clearance by the liver or kidneys and also increases plasma half-life alongside the volume of distribution. The polymer, moreover, guards the drug against deprivation [98]. PDC has three main constituents: a decomposable linker, soluble polymer support, and antineoplastic drug covalently associated that are deactivated as a conjugate. The polymer-drug linker is taken to discharge and retrigger the involved drug fragments [99].

\subsubsection{Polymersome nano-particles.}

Polymersomes (Ps) have enticed fast-developing concentration founded on their interesting phenomena of aggregation, virus, and cell-mimicking dimensions plus roles [100]. Ps contain an aquatic dissolvent in the base, have confined by a two-layer membrane. This twolayer membrane is composed inward as well as outward of the hydrophobic middle part of the membrane with hydrated hydrophilic coronas. The aquatic core possibly is used for the encapsulation of therapeutic hydrophilic particulates, and the membrane can join hydrophobic drugs within its hydrophobic part [101-103]. The presence of a hydrophilic PEG brush on the surface will decrease the protein absorption onto the Ps throughout the plasma flow.

\subsubsection{Carbon-based nanoparticles.}

The carbon nanotube-mediated medication transport method has great upturned significance for its biologically compatible substrate. The external barriers of the nanotubes are functionally allocating target specific molecules, and medicines can be disseminated to exact destinations [104]. These are elaborated in all solvents while yielding several healthiness concerns. The individualization of the surface with chemical change reduces water-soluble 
carbon nanotubes. The coating of nanoparticles or strong nerves with complement proteins is affecting to lessen muscle impairment and aid in treating inflammatory diseases like PD, Huntington's, ALS, and Alzheimer's.

\subsection{Challenges and Future Prospective.}

\subsubsection{Requirement of observing non-motor signs.}

The improvement of wearable systems for selecting people with PD's has been combined intensely with the features of the motor aspects that are likewise (e.g., tremor, bradykinesia), albeit with lower sensitivity, specificity and evaluated by clinical scales [105107]. Despite current improvements in the appraisal of motor symptoms, for example, tremor, these endpoints regularly allow just unassuming quantifiable agreement with dealings of excellence of life $[108,109]$. Patient's desires and source of disability repeatedly develop from non-motor deficits. Unfortunately, rare investigations have concentrated on catching the changes of these intricate ailment indications [110,111]. The advancement of TOMs for nonmotor endpoints has depended upon labor-intensive or computerized, laboratory-based measurements (e.g., cognitive function, heart rate, blood pressure changes, or sleep). [112,113].

\subsubsection{Restrictions of sensors used to observe motor symptoms.}

Biomechanical sensors, for example, magnetometers and accelerometers, are appropriate for the recognition of bradykinesia, tremor, and motor impediments, like dyskinesia. But the gathered records in the home and community sites utilizing these sensors don't mostly ensure satisfactory facts to complete a dependable clinical evaluation of motor side effects. For example, it is hard to derive that, through the sensor data lonely and if the slowness of development can be utilized as an intermediary of bradykinesia $[108,109]$.

\subsubsection{Divergence between clinical requirements and investigation.}

The endpoint that might be appropriate for a medical report is not important or relevant in clinical consideration. The significance of specific TOMs in evaluating the effect of parkinsonian side effects on the sufferer's satisfaction might be hard to assess. For example, fluctuations in motor indications and inconveniences, dyskinesia may have an intricate computable link with proportions of disabilities [114].

\subsubsection{Absence of compatibility among wearable methods.}

Maximum wearable systems created to monitor people with PD are not good with each other. Thus, it might be bulky or difficult to consolidate information accumulated by TOMs created or by various producers. This makes it hard to direct behavioral changes or therapeutic mediations. Moreover, a device created by various producers for a similar reason may not generally yield a similar outcome, bringing up issues about the validity of the mathematical algorithms that manage the data processing. [115]

\subsubsection{Practical restrictions in consumer engagement.}

Software and hardware components of wearable systems are not frequently reasonable to adopt [116]. Right now, patient and parental figure commitment with wearable and mobile technology are humbled, as they appeared by an ongoing report exhibiting that $32 \%$ of clients stop utilizing wearables following a half year. There is also a great failure rate amongst cell 
phone applications clients: $26 \%$ of applications are utilized just once, and $74 \%$ of applications are not utilized more than multiple times [117,118]. The absence of inspiration to utilize selfobserving systems might not be misjudged, particularly in the absence of meaningful feedback provided to their users. Primary evidence recommends that patients strengthen and their consideration as dynamic players in the improvement of research exercises may positively impact compliances [119].

\subsubsection{Standard measurement platform.}

A few organizations have tried or are surveying an assortment of techniques to test individual motor and non-motor constructs. To maintain a strategic distance from duplication of investments and efforts, the privileges exist to distinguish the technologies and approaches with the most flexibility, most restless and doctor encumbrance, and least expenses.

\subsubsection{Multi-domain measurements.}

Tremor estimation might be fully superfluous to people with a motor or posturalinstability gait-disorder (PIGD), the phenotype of PD. Systems that are intended for multispace information could give analysts and clinicians, the adaptability of picking, the antennas to screen people with various phenotypes of PD.

\subsubsection{Superior subtype and phenotype.}

Tremor and tremor fewer deviations of PD are categorized as clinical phenotypes for a primarily observational recommendation, with major heterogeneity. Moreover, these medical phenotypes likely occur a few sickness subtypes characterized via autonomic, intellectual or different areas of disability that could be caught by multichannel schemes [120]

\subsubsection{Accuracy of treatment.}

By recognizing territories of dysfunction and their link with treatments, TOMs can be utilized to give consumers feedback to patients as well as potentially set conditions that "anticipate" the sensitivity to particular management ideal models.

\subsubsection{Closed-loop (feedback) methods.}

The pieces of information gathered for utilizing wearable sensors could be utilized to elicit device based intercessions. Much as ECG detecting is utilized in cardiovascular defibrillators to provoke the conveyance of incitement beats, information gathered from sensors situated on the appendages and trunk could be utilized to predict, for example, the onset of a freezing episode [121, 122].

\subsubsection{Real-time sign tracking.}

TOMs could bid constant, rater-free information, interestingly with clinical assessments that depend upon emotional data assembled during irregular in-center assessments [123].

3.4.12. The promise of remote monitoring.

TOMs dependent on the utilization of wearable systems may develop human services conveyance by assessing, while patients are absent in the clinic. This chance is especially 
applicable in favor of people with PD who resides in zones with restricted care. TOMs could deliver environmentally effective data to support clinicians' monitor responses to remedy and customize administration to improve. Remote checking offers the prospects for social insurance cost reduction $[124,125]$.

\section{Conclusion}

Applications of nanotechnology have all the opportunity to upset the medication conveyance systems in degenerative infections. The bio-manufacture of medications by cautious and fundamental determination of polymers is one more factor to be considered. An existing uniformity of advancement of nano-technological curative methodology and welfare of human social insurance contains major worry as the area of nanotechnology is yet hopeful. To consider the basic system of medication, ailments, as well as interpretation of outcomes by way of a coordinated effort of researchers along with physicians, are extreme goals of the advancement of nano-medicine. Nowadays, the study has shown a wide range of utilizations of nanotechnology-based medication conveyance schemes that are being utilized to fight against Parkinson's disease. Through the colossal endeavors to find biomarkers and make nano-medicines focusing on the biomarkers in the previous decade, various investigations have gained productive ground to conquer current constraints that hinder the clinical interpretation of CNS-focusing on prescriptions. These investigations have completely demonstrated the unfathomable capacities of the half, and half nanoparticle-based treatment of Parkinson's disease for identifying or treating neurological scatters both in vitro and in vivo, which may prompt accomplishment on the clinical interpretation toward the end.

\section{Funding}

This research received no external funding.

\section{Acknowledgments}

The authors are grateful to the Department of Pharmacy, Daffodil International University, Dhaka, Bangladesh, for providing permission and all sorts of supports to conduct this research.

\section{Conflicts of Interest}

The authors declare no conflict of interest.

\section{References}

1. Sanchez-Mut, J.V.; Heyn, H.; Vidal, E.; Moran, S.; Sayols, S.; Delgado-Morales, R.; Schultz, M.D.; Ansoleaga, B.; Garcia-Esparcia, P.; Pons-Espinal, M.; de Lagran, M.M.; Dopazo, J.; Rabano, A.; Avila, J.; Dierssen, M.; Lott, I.; Ferrer, I.; Ecker, J.R.; Esteller, M. Human DNA methylomes of neurodegenerative diseases show common epigenomic patterns. Translational Psychiatry 2016, 6, e718-e718, https://doi.org/10.1038/tp.2015.214.

2. Chen,W.W.; Zhang,X.; Huang,W.J. Role of neuroinflammation in neurodegenerative diseases. Molecular medicine reports 2016, 13, 3391-3396, https://doi.org/10.3892/mmr.2016.4948.

3. Hirsch, E.C.; Jenner, P.; Przedborski, S. Pathogenesis of Parkinson's disease. Movement Disorders 2013, 28 , 24-30, https://doi.org/10.1002/mds.25032.

4. Zeng, X.S.; Geng, W.S.; Jia, J.J.; Chen, L.; Zhang, P.P. Cellular and Molecular Basis of Neurodegeneration in Parkinson Disease. Frontiers in Aging Neuroscience 2018, 10, https://doi.org/10.3389/fnagi.2018.00109.

5. Pringsheim, T.; Jette, N.; Frolkis, A.; Steeves, T.D.L. The prevalence of Parkinson's disease: A systematic review and meta-analysis. Movement Disorders 2014, 29, 1583-1590, https://doi.org/10.1002/mds.25945. 
6. $\quad$ Espay, A.J.; Vizcarra, J.A.; Marsili, L.; Lang, A.E.; Simon, D.K.; Merola, A.; Josephs, K.A.; Fasano, A.; Morgante, F.; Savica, R.; Greenamyre, J.T.; Cambi, F.; Yamasaki, T.R.; Tanner, C.M.; Gan-Or, Z.; Litvan, I.; Mata, I.F.; Zabetian, C.P.; Brundin, P.; Fernandez, H.H.; Standaert, D.G.; Kauffman, M.A.; Schwarzschild, M.A.; Sardi, S.P.; Sherer, T.; Perry, G.; Leverenz, J.B. Revisiting protein aggregation as pathogenic in sporadic Parkinson and Alzheimer diseases. Neurology 2019, 92, https://doi.org/10.1212/WNL.0000000000006926.

7. Marchetti, B.; Abbracchio, M.P. To be or not to be (inflamed) \&\#x2013; is that the question in antiinflammatory drug therapy of neurodegenerative disorders? Trends in Pharmacological Sciences 2005, 26, 517-525, https://doi.org/10.1016/j.tips.2005.08.007.

8. Kowal, S.L.; Dall, T.M.; Chakrabarti, R.; Storm, M.V.; Jain, A. The current and projected economic burden of Parkinson's disease in the United States. Movement Disorders 2013, 28, 311-318, https://doi.org/10.1002/mds.25292.

9. Ragothaman, M.; Govindappa, S.T.; Rattihalli, R.; Subbakrishna, D.K.; Muthane, U.B. Direct costs of managing Parkinson's disease in india: Concerns in a developing country. Movement Disorders 2006, 21, 1755-1758, https://doi.org/10.1002/mds.21035.

10. Goetz, C.G. Charcot on Parkinson's disease. Movement Disorders 1986, 1, 27-32, https://doi.org/10.1002/mds.870010104.

11. Berg, D.; Lang, A.E.; Postuma, R.B.; Maetzler, W.; Deuschl, G.; Gasser, T.; Siderowf, A.; Schapira, A.H.; Oertel, W.; Obeso, J.A.; Olanow, C.W.; Poewe, W.; Stern, M. Changing the research criteria for the diagnosis of Parkinson's disease: obstacles and opportunities. The Lancet Neurology 2013, 12, 514-524, https://doi.org/10.1016/S1474-4422(13)70047-4.

12. Miller, D.B.; O’Callaghan, J.P. Biomarkers of Parkinson's disease: Present and future. Metabolism - Clinical and Experimental 2015, 64, S40-S46, https://doi.org/10.1016/j.metabol.2014.10.030.

13. Mattson, M.P.; Arumugam, T.V. Hallmarks of Brain Aging: Adaptive and Pathological Modification by Metabolic States. Cell Metabolism 2018, 27, 1176-1199, https://doi.org/10.1016/j.cmet.2018.05.011.

14. Espay, A.J.; Bonato, P.; Nahab, F.B.; Maetzler, W.; Dean, J.M.; Klucken, J.; Eskofier, B.M.; Merola, A.; Horak, F.; Lang, A.E.; Reilmann, R.; Giuffrida, J.; Nieuwboer, A.; Horne, M.; Little, M.A.; Litvan, I.; Simuni, T.; Dorsey, E.R.; Burack, M.A.; Kubota, K.; Kamondi, A.; Godinho, C.; Daneault, J.-F.; Mitsi, G.; Krinke, L.; Hausdorff, J.M.; Bloem, B.R.; Papapetropoulos, S.; on behalf of the Movement Disorders Society Task Force on, T. Technology in Parkinson's disease: Challenges and opportunities. Movement Disorders 2016, 31, 1272-1282, https://doi.org/10.1002/mds.26642.

15. Mollaamin, F. Methamphetamine causes the exhilaration in the brain by dumping dopamine. Biointerface research in applied chemistry 2019,9(2),3884-3889, https://doi.org/10.33263/BRIAC92.884889.

16. Postuma, R.B.; Berg, D.; Stern, M.; Poewe, W.; Olanow, C.W.; Oertel, W.; Obeso, J.; Marek, K.; Litvan, I.; Lang, A.E.; Halliday, G.; Goetz, C.G.; Gasser, T.; Dubois, B.; Chan, P.; Bloem, B.R.; Adler, C.H.; Deuschl, G. MDS clinical diagnostic criteria for Parkinson's disease. Movement Disorders 2015, 30, 1591-1601, https://doi.org/10.1002/mds.26424.

17. Mollenhauer, B.; Trautmann, E.; Sixel-Döring, F.; Wicke, T.; Ebentheuer, J.; Schaumburg, M.; Lang, E.; Focke, N.K.; Kumar, K.R.; Lohmann, K.; Klein, C.; Schlossmacher, M.G.; Kohnen, R.; Friede, T.; Trenkwalder, C. Nonmotor and diagnostic findings in subjects with de novo Parkinson disease of the DeNoPa cohort. Neurology 2013, 81, 1226-1234, https://doi.org/10.1212/WNL.0b013e3182a6cbd5.

18. Gerlach, M.; Maetzler, W.; Broich, K.; Hampel, H.; Rems, L.; Reum, T.; Riederer, P.; Stöffler, A.; Streffer, J.; Berg, D. Biomarker candidates of neurodegeneration in Parkinson's disease for the evaluation of diseasemodifying therapeutics. Journal of Neural Transmission 2012, 119, 39-52, https://doi.org/10.1007/s00702011-0682-x.

19. Nayak,R.; Nanda, B. A review on formulation, design of nanostructured material through oil-in-water microemulsion. Letters in applied nanobioscience 2020,9(2),945-951, https://doi.org/10.33263/LIANBS92.945951.

20. Adhikary, R.R.; Sandbhor, P.; Banerjee, R. Nanotechnology platforms in Parkinson's Disease. ADMET and DMPK. 2015, 3, 155-81, http://dx.doi.org/10.5599/admet.3.3.189.

21. Kaushik, A.C.; Bharadwaj, S.; Kumar, S.; Wei, D.-Q. Nano-particle mediated inhibition of Parkinson's disease using computational biology approach. Scientific Reports 2018, 8, https://doi.org/10.1038/s41598018-27580-1.

22. Torres-Ortega, P.V.; Saludas, L.; Hanafy, A.S.; Garbayo, E.; Blanco-Prieto, M.J. Micro- and nanotechnology approaches to improve Parkinson's disease therapy. Journal of Controlled Release 2019, 295, 201-213, https://doi.org/10.1016/j.jconrel.2018.12.036.

23. McNaught, K.S.P.; Olanow, C.W. Protein aggregation in the pathogenesis of familial and sporadic Parkinson's disease. Neurobiology of Aging 2006, 27, 530-545, https://doi.org/10.1016/j.neurobiolaging.2005.08.012.

24. Dong, X. Current Strategies for Brain Drug Delivery. Theranostics 2018, 8, 1481-1493, https://doi.org/10.7150/thno.21254.

25. Jenner, P.; Olanow, C.W. The pathogenesis of cell death in Parkinson's disease. Neurology 2006, 66, S24S36, https://doi.org/10.1212/wnl.66.10_suppl_4.s24. 
26. Simon, D.K.; Tanner, C.M.; Brundin, P. Parkinson Disease Epidemiology, Pathology, Genetics, and Pathophysiology. Clinics in Geriatric Medicine 2020, 36, 1-12, https://doi.org/10.1016/j.cger.2019.08.002.

27. Saeedi, M.; Eslamifar, M.; Khezri, K.; Dizaj, S.M. Applications of nanotechnology in drug delivery to the central nervous system. Biomedicine \& Pharmacotherapy 2019, 111, 666-675, https://doi.org/10.1016/j.biopha.2018.12.133.

28. Vissers, C.; Ming, G.-1.; Song, H. Nanoparticle technology and stem cell therapy team up against neurodegenerative disorders. Advanced Drug Delivery Reviews 2019, 148, 239-251, https://doi.org/10.1016/j.addr.2019.02.007.

29. Duffy, P.E.; Tennyson, V.M. Phase and Electron Microscopic Observations of Lewy Bodies and Melanin Granules in the Substantia Nigra and Locus Caeruleus in Parkinson's Disease* ${ }^{\dagger}$. Journal of Neuropathology \& Experimental Neurology 1965, 24, 398-414, https://doi.org/10.1097/00005072-196507000-00003.

30. Goldman, J.; Yen, S.; Chiu, F.; Peress, N. Lewy bodies of Parkinson's disease contain neurofilament antigens. Science 1983, 221, 1082-1084, https://doi.org/10.1126/science.6308771.

31. Hill, W.D.; Lee, V.M.Y.; Hurtig, H.I.; Murray, J.M.; Trojanowski, J.Q. Epitopes located in spatially separate domains of each neurofilament subunit are present in parkinson's disease lewy bodies. Journal of Comparative Neurology 1991, 309, 150-160, https://doi.org/10.1002/cne.903090111.

32. Re, F.; Gregori, M.; Masserini, M. Nanotechnology for neurodegenerative disorders. Maturitas 2012, 73, 45-51, https://doi.org/10.1016/j.maturitas.2011.12.015.

33. Fergusson, J.; Landon, M.; Lowe, J.; Dawson, S.P.; Layfield, R.; Hanger, D.P.; Mayer, R.J. Pathological lesions of Alzheimer's disease and dementia with Lewy bodies brains exhibit immunoreactivity to an ATPase that is a regulatory subunit of the $26 \mathrm{~S}$ proteasome. Neuroscience Letters 1996, 219, 167-170, https://doi.org/10.1016/S0304-3940(96)13192-X.

34. Ii, K.; Ito, H.; Tanaka, K.; Hirano, A. Immunocytochemical Co-localization of the Proteasome in Ubiquitinated Structures in Neurodegenerative Diseases and the Elderly. Journal of Neuropathology \& Experimental Neurology 1997, 56, 125-131, https://doi.org/10.1097/00005072-199702000-00002.

35. Bridi, J.C.; Hirth, F. Mechanisms of $\alpha$-Synuclein Induced Synaptopathy in Parkinson's Disease. Frontiers in Neuroscience 2018, 12, https://doi.org/10.3389/fnins.2018.00080.

36. Bentea, E.; Verbruggen, L.; Massie, A. The Proteasome Inhibition Model of Parkinson's Disease. J Parkinsons Dis. 2017, 7, 31-63, https://doi.org/10.3233/JPD-160921.

37. Braak, H.; Ghebremedhin, E.; Rüb, U.; Bratzke, H.; Del Tredici, K. Stages in the development of Parkinson's disease-related pathology. Cell and Tissue Research 2004, 318, 121-134, https://doi.org/10.1007/s00441004-0956-9.

38. Riehemann, K.; Schneider, S.W.; Luger, T.A.; Godin, B.; Ferrari, M.; Fuchs, H. Nanomedicine-Challenge and Perspectives. Angewandte Chemie International Edition 2009, 48, 872-897, https://doi.org/10.1002/anie.200802585.

39. Teleanu, M.D.; Negut, I.; Grumezescu, V.; Grumezescu, M.A.; Teleanu, I.R. Nanomaterials for Drug Delivery to the Central Nervous System. Nanomaterials 2019, 9, https://doi.org/10.3390/nano9030371.

40. Leyva-Gómez, G.; Cortés, H.; Magaña, J.J.; Leyva-García, N.; Quintanar-Guerrero, D.; Florán, B. Nanoparticle technology for treatment of Parkinson's disease: the role of surface phenomena in reaching the brain. Drug Discovery Today 2015, 20, 824-837, https://doi.org/10.1016/j.drudis.2015.02.009.

41. Goldsmith, M.; Abramovitz, L.; Peer, D. Precision Nanomedicine in Neurodegenerative Diseases. ACS Nano 2014, 8, 1958-1965, https://doi.org/10.1021/nn501292z.

42. McDannold, N.; Arvanitis, C.D.; Vykhodtseva, N.; Livingstone, M.S. Temporary Disruption of the BloodBrain Barrier by Use of Ultrasound and Microbubbles: Safety and Efficacy Evaluation in Rhesus Macaques. Cancer Research 2012, 72, 3652-3663, https://doi.org/10.1158/0008-5472.CAN-12-0128.

43. Smith, M.W.; Gumbleton, M. Endocytosis at the blood-brain barrier: From basic understanding to drug delivery strategies. Journal of Drug Targeting 2006, 14, 191-214, https://doi.org/10.1080/10611860600650086.

44. Qu, M.; Lin, Q.; Huang, L.; Fu, Y.; Wang, L.; He, S.; Fu, Y.; Yang, S.; Zhang, Z.; Zhang, L.; Sun, X. Dopamine-loaded blood exosomes targeted to brain for better treatment of Parkinson's disease. Journal of Controlled Release 2018, 287, 156-166, https://doi.org/10.1016/j.jconrel.2018.08.035.

45. Qu, M.; Lin, Q.; He, S.; Wang, L.; Fu, Y.; Zhang, Z.; Zhang, L. A brain targeting functionalized liposomes of the dopamine derivative N-3,4-bis(pivaloyloxy)-dopamine for treatment of Parkinson's disease. Journal of Controlled Release 2018, 277, 173-182, https://doi.org/10.1016/j.jconrel.2018.03.019.

46. Song, Q.; Huang, M.; Yao, L.; Wang, X.; Gu, X.; Chen, J.; Chen, J.; Huang, J.; Hu, Q.; Kang, T.; Rong, Z.; Qi, H.; Zheng, G.; Chen, H.; Gao, X. Lipoprotein-Based Nanoparticles Rescue the Memory Loss of Mice with Alzheimer's Disease by Accelerating the Clearance of Amyloid-Beta. ACS Nano 2014, 8, 2345-2359, https://doi.org/10.1021/nn4058215.

47. Wang, N.; Jin, X.; Guo, D.; Tong, G.; Zhu, X. Iron Chelation Nanoparticles with Delayed Saturation as an Effective Therapy for Parkinson Disease. Biomacromolecules 2017, 18, 461-474, https://doi.org/10.1021/acs.biomac.6b01547. 
48. Saraiva, C.; Praça, C.; Ferreira, R.; Santos, T.; Ferreira, L.; Bernardino, L. Nanoparticle-mediated brain drug delivery: Overcoming blood-brain barrier to treat neurodegenerative diseases. Journal of Controlled Release 2016, 235, 34-47, https://doi.org/10.1016/j.jconrel.2016.05.044.

49. Georgieva, V.J.; Hoekstra, D.; Zuhorn, S.I. Smuggling Drugs into the Brain: An Overview of Ligands Targeting Transcytosis for Drug Delivery across the Blood-Brain Barrier. Pharmaceutics 2014, 6, 557-583, https://doi.org/10.3390/pharmaceutics6040557.

50. Monsalve, Y.; Tosi, G.; Ruozi, B.; Belletti, D.; Vilella, A.; Zoli, M.; Vandelli, M.A.; Forni, F.; López, B.L.; Sierra, L. PEG-g-chitosan nanoparticles functionalized with the monoclonal antibody OX26 for brain drug targeting. Nanomedicine 2015, 10, 1735-1750, https://doi.org/10.2217/nnm.15.29.

51. Niazi, M.; Zakeri-Milani, P.; Najafi Hajivar, S.; Soleymani Goloujeh, M.; Ghobakhlou, N.; Shahbazi Mojarrad, J.; Valizadeh, H. Nano-based strategies to overcome p-glycoprotein-mediated drug resistance. Expert Opinion on Drug Metabolism \& Toxicology 2016, 12, 1021-1033, https://doi.org/10.1080/17425255.2016.1196186.

52. Sridhar, V.; Gaud, R.; Bajaj, A.; Wairkar, S. Pharmacokinetics and pharmacodynamics of intranasally administered selegiline nanoparticles with improved brain delivery in Parkinson's disease. Nanomedicine: Nanotechnology, Biology and Medicine 2018, 14, 2609-2618, https://doi.org/10.1016/j.nano.2018.08.004.

53. Malmo, J.; Sandvig, A.; Vårum, K.M.; Strand, S.P. Nanoparticle Mediated P-Glycoprotein Silencing for Improved Drug Delivery across the Blood-Brain Barrier: A siRNA-Chitosan Approach. PLOS ONE 2013, 8, https://doi.org/10.1371/journal.pone.0054182.

54. Aly, A.E.E.; Harmon, B.T.; Padegimas, L.; Sesenoglu-Laird, O.; Cooper, M.J.; Waszczak, B.L. Intranasal Delivery of pGDNF DNA Nanoparticles Provides Neuroprotection in the Rat 6-Hydroxydopamine Model of Parkinson's Disease. Molecular Neurobiology 2019, 56, 688-701, https://doi.org/10.1007/s12035-0181109-6.

55. Hanada, S.; Fujioka, K.; Inoue, Y.; Kanaya, F.; Manome, Y.; Yamamoto, K. Cell-Based in Vitro BloodBrain Barrier Model Can Rapidly Evaluate Nanoparticles' Brain Permeability in Association with Particle Size and Surface Modification. International Journal of Molecular Sciences 2014, 15, https://doi.org/10.3390/ijms15021812.

56. Kreuter, J. Drug delivery to the central nervous system by polymeric nanoparticles: What do we know? Advanced Drug Delivery Reviews 2014, 71, 2-14, https://doi.org/10.1016/j.addr.2013.08.008.

57. Vergoni, A.V.; Tosi, G.; Tacchi, R.; Vandelli, M.A.; Bertolini, A.; Costantino, L. Nanoparticles as drug delivery agents specific for CNS: in vivo biodistribution. Nanomedicine: Nanotechnology, Biology and Medicine 2009, 5, 369-377, https://doi.org/10.1016/j.nano.2009.02.005.

58. Kante, B.; Couvreur, P.; Dubois-Krack, G.; De Meester, C.; Guiot, P.; Roland, M.; Mercier, M.; Speiseru, P. Toxicity of Polyalkylcyanoacrylate Nanoparticles I: Free Nanoparticles. Journal of Pharmaceutical Sciences 1982, 71, 786-790, https://doi.org/10.1002/jps.2600710716.

59. Limayem, I.; Charcosset, C.; Fessi, H. Purification of nanoparticle suspensions by a concentration/diafiltration process. Separation and Purification Technology 2004, 38, 1-9, https://doi.org/10.1016/j.seppur.2003.10.002.

60. Freitas, C.; Müller, R.H. Effect of light and temperature on zeta potential and physical stability in solid lipid nanoparticle (SLNTM) dispersions. International Journal of Pharmaceutics 1998, 168, 221-229, https://doi.org/10.1016/S0378-5173(98)00092-1.

61. Gulati, N.; Nagaich, U.; Saraf, S. Fabrication and in vitro characterization of polymeric nanoparticles for Parkinson's therapy: a novel approach. Brazilian Journal of Pharmaceutical Sciences 2014, 50, 869-876, http://dx.doi.org/10.1590/S1984-82502014000400022.

62. Müller, R.H.; Mäder, K.; Gohla, S. Solid lipid nanoparticles (SLN) for controlled drug delivery - a review of the state of the art. European Journal of Pharmaceutics and Biopharmaceutics 2000, 50, 161-177, https://doi.org/10.1016/s0939-6411(00)00087-4.

63. Abdelwahed, W.; Degobert, G.; Stainmesse, S.; Fessi, H. Freeze-drying of nanoparticles: Formulation, process and storage considerations. Advanced Drug Delivery Reviews 2006, 58, 1688-1713, https://doi.org/10.1016/j.addr.2006.09.017.

64. Kaur, I.P.; Bhandari, R.; Bhandari, S.; Kakkar, V. Potential of solid lipid nanoparticles in brain targeting. Journal of Controlled Release 2008, 127, 97-109, https://doi.org/10.1016/j.jconrel.2007.12.018.

65. Fundarò, A.; Cavalli, R.; Bargoni, A.; Vighetto, D.; Zara, G.P.; Gasco, M.R. Non-stealth and stealth solid lipid nanoparticles (SLN) carrying doxorubicin: pharmacokinetics and tissue distribution after i.v. administration to rats. Pharmacological Research 2000, 42, 337-343, https://doi.org/10.1006/phrs.2000.0695.

66. Peira, E.; Marzola, P.; Podio, V.; Aime, S.; Sbarbati, A.; Gasco, M.R. In Vitro and In Vivo Study of Solid Lipid Nanoparticles Loaded with Superparamagnetic Iron Oxide. Journal of Drug Targeting 2003, 11, 1924, https://doi.org/10.1080/1061186031000086108.

67. Keck, C.M.; Müller, R.H. Drug nanocrystals of poorly soluble drugs produced by high pressure homogenisation. European Journal of Pharmaceutics and Biopharmaceutics 2006, 62, 3-16, https://doi.org/10.1016/j.ejpb.2005.05.009. 
68. Connolly, B.S.; Lang, A.E. Pharmacological Treatment of Parkinson Disease: A Review. JAMA 2014, 311, 1670-1683, https://doi.org/10.1001/jama.2014.3654.

69. Huang, X.; El-Sayed, M.A. Gold nanoparticles: Optical properties and implementations in cancer diagnosis and photothermal therapy. Journal of Advanced Research 2010, 1, 13-28, https://doi.org/10.1016/j.jare.2010.02.002.

70. Arvizo, R.R.; Bhattacharyya, S.; Kudgus, R.A.; Giri, K.; Bhattacharya, R.; Mukherjee, P. Intrinsic therapeutic applications of noble metal nanoparticles: past, present and future. Chemical Society Reviews 2012, 41, 2943-2970, https://doi.org/10.1039/c2cs15355f.

71. Thakkar, K.N.; Mhatre, S.S.; Parikh, R.Y. Biological synthesis of metallic nanoparticles. Nanomedicine: Nanotechnology, Biology and Medicine 2010, 6, 257-262, https://doi.org/10.1016/j.nano.2009.07.002.

72. Anita, E.N.R.; Torres, S.A.L.; Pineda, V.J.; Espinosa, C.M.J. ; de la Fuente-Hernandez, J.; Manuel, C.V. Toxicology of antimicrobial nanoparticles for prosthetic devices. Int. J. Nanomed. 2014, 9, 3999-4006, https://doi.org/10.2147/ijn.s63064.

73. Lokina, S.; Narayanan, V. Antimicrobial and anticancer activity of gold nanoparticles synthesized from grapes fruit extract. Chem. Sci. Trans. 2013, 2(S1), S105-S110, https://doi.org/10.7598/cst2013.22.

74. Abdal Dayem, A.; Lee, B.S.; Choi, Y.H.; Cho, S.-G. Silver Nanoparticles: Two-Faced Neuronal Differentiation-Inducing Material in Neuroblastoma (SH-SY5Y) Cells. International Journal of Molecular Sciences 2018, 19, https://doi.org/10.3390/ijms19051470.

75. Zhang, J.P.; Chen, P.; Sun, C.H.; Hu, X.J. Sonochemical synthesis of colloidal silver catalysts for reduction of complexing silver in DTR system. Applied Catalysis A: General 2004, 266, 49-54, https://doi.org/10.1016/j.apcata.2004.01.025.

76. Zhang, W.; Qiao, X.; Chen, J.; Wang, H. Preparation of silver nanoparticles in water-in-oil AOT reverse micelles. Journal of Colloid and Interface Science 2006, 302, 370-373, https://doi.org/10.1016/j.jcis.2006.06.035.

77. Chimentão, R.J.; Kirm, I.; Medina, F.; Rodríguez, X.; Cesteros, Y.; Salagre, P.; Sueiras, J.E. Different morphologies of silver nanoparticles as catalysts for the selective oxidation of styrene in the gas phase. Chemical Communications 2004, 7, 846-847, https://doi.org/10.1039/B400762J.

78. He, B.; Tan, J.J.; Liew, K.Y.; Liu, H. Synthesis of size controlled Ag nanoparticles. Journal of Molecular Catalysis A: Chemical 2004, 221, 121-126, https://doi.org/10.1016/j.molcata.2004.06.025.

79. Yu, D.G. Formation of colloidal silver nanoparticles stabilized by Na+-poly( $\gamma$-glutamic acid)-silver nitrate complex via chemical reduction process. Colloids and Surfaces B: Biointerfaces 2007, 59, 171-178, https://doi.org/10.1016/j.colsurfb.2007.05.007.

80. Liu, Y.-C.; Lin, L.-H. New pathway for the synthesis of ultrafine silver nanoparticles from bulk silver substrates in aqueous solutions by sonoelectrochemical methods. Electrochemistry Communications 2004, 6, 1163-1168, https://doi.org/10.1016/j.elecom.2004.09.010.

81. Mallick, K.; Witcomb, M.J.; Scurrell, M.S. Self-assembly of silver nanoparticles in a polymer solvent: formation of a nanochain through nanoscale soldering. Materials Chemistry and Physics 2005, 90, 221-224, https://doi.org/10.1016/j.matchemphys.2004.10.030.

82. Sperling, R.A.; Rivera Gil, P.; Zhang, F.; Zanella, M.; Parak, W.J. Biological applications of gold nanoparticles. Chemical Society Reviews 2008, 37, 1896-1908, https://doi.org/10.1039/B712170A.

83. Mukherjee, P.; Bhattacharya, R.; Wang, P.; Wang, L.; Basu, S.; Nagy, J.A.; Atala, A.; Mukhopadhyay, D.; Soker, S. Antiangiogenic Properties of Gold Nanoparticles. Clinical Cancer Research 2005, 11, 3530-3534, https://doi.org/10.1158/1078-0432.CCR-04-2482.

84. Gao, W.; Xu, K.; Ji, L.; Tang, B. Effect of gold nanoparticles on glutathione depletion-induced hydrogen peroxide generation and apoptosis in HL7702 cells. Toxicology Letters 2011, 205, 86-95, https://doi.org/10.1016/j.toxlet.2011.05.1018.

85. Ghosh, R.; Singh, L.C.; Shohet, J.M.; Gunaratne, P.H. A gold nanoparticle platform for the delivery of functional microRNAs into cancer cells. Biomaterials 2013, 34, 807-816, https://doi.org/10.1016/j.biomaterials.2012.10.023.

86. Markman, J.L.; Rekechenetskiy, A.; Holler, E.; Ljubimova, J.Y. Nanomedicine therapeutic approaches to overcome cancer drug resistance. Advanced Drug Delivery Reviews 2013, 65, 1866-1879, https://doi.org/10.1016/j.addr.2013.09.019.

87. Visaria, R.K.; Griffin, R.J.; Williams, B.W.; Ebbini, E.S.; Paciotti, G.F.; Song, C.W.; Bischof, J.C. Enhancement of tumor thermal therapy using gold nanoparticle-assisted tumor necrosis factor- $\alpha$ delivery. Molecular Cancer Therapeutics 2006, 5, 1014-1020, https://doi.org/10.1158/1535-7163.MCT-05-0381.

88. Lee, J.-M.; Yoon, T.-J.; Cho, Y.-S. Recent Developments in Nanoparticle-Based siRNA Delivery for Cancer Therapy. BioMed Research International 2013, 2013, https://doi.org/10.1155/2013/782041.

89. Pathak, J.; Sonker, A. S.; Rajneesh, ; Singh, B.; Kumar, D.;Sinha, R. P. Synthesis of silver nanoparticles from extracts of Scytonema geitleri HKAR-12 and their in vitro antibacterial and antitumor potentials. Letters in applied nanobioscience 2019,8(3),576-585, https://doi.org/10.33263/LIANBS83.576585.

90. O'Neal, D.P.; Hirsch, L.R.; Halas, N.J.; Payne, J.D.; West, J.L. Photo-thermal tumor ablation in mice using near infrared-absorbing nanoparticles. Cancer Letters 2004, 209, 171-176, https://doi.org/10.1016/j.canlet.2004.02.004. 
91. Hu, K.; Chen, X.; Chen, W.; Zhang, L.; Li, J.; Ye, J.; Zhang, Y.; Zhang, L.; Li, C.-H.; Yin, L.; Guan, Y.-Q. Neuroprotective effect of gold nanoparticles composites in Parkinson's disease model. Nanomedicine: Nanotechnology, Biology and Medicine 2018, 14, 1123-1136, https://doi.org/10.1016/j.nano.2018.01.020.

92. Lee, J.; Kim, H.Y.; Zhou, H.; Hwang, S.; Koh, K.; Han, D.-W.; Lee, J. Green synthesis of phytochemicalstabilized Au nanoparticles under ambient conditions and their biocompatibility and antioxidative activity. Journal of Materials Chemistry 2011, 21, 13316-13326, https://doi.org/10.1039/C1JM11592H.

93. Gao, G.; Chen, R.; He, M.; Li, J.; Li, J.; Wang, L.; Sun, T. Gold nanoclusters for Parkinson's disease treatment. Biomaterials 2019, 194, 36-46, https://doi.org/10.1016/j.biomaterials.2018.12.013.

94. Kim, J.S.; Kuk, E.; Yu, K.N.; Kim, J.H.; Park, S.J.; Lee, H.J.; Kim, S.H.; Park, Y.K.; Park, Y.H.; Hwang, C.Y.; Kim, Y.K.; Lee, Y.S.; Jeong, D.H.; Cho, M.H. Antimicrobial effects of silver nanoparticles. Nanomedicine: Nanotechnology, Biology and Medicine 2007, 3, 95-101, https://doi.org/10.1016/j.nano.2006.12.001.

95. Rao, P.V.; Nallappan, D.; Madhavi, K.; Rahman, S.; Jun Wei, L.; Gan, S.H. Phytochemicals and Biogenic Metallic Nanoparticles as Anticancer Agents. Oxidative Medicine and Cellular Longevity 2016, 2016, https://doi.org/10.1155/2016/3685671.

96. Ahamed, M.; AlSalhi, M.S.; Siddiqui, M.K.J. Silver nanoparticle applications and human health. Clinica Chimica Acta 2010, 411, 1841-1848, https://doi.org/10.1016/j.cca.2010.08.016.

97. Teleanu, M.D.; Chircov, C.; Grumezescu, M.A.; Volceanov, A.; Teleanu, I.R. Impact of Nanoparticles on Brain Health: An Up to Date Overview. Journal of Clinical Medicine 2018, 7, https://doi.org/10.3390/jcm7120490.

98. Yurkovetskiy, A.V.; Fram, R.J. XMT-1001, a novel polymeric camptothecin pro-drug in clinical development for patients with advanced cancer. Advanced Drug Delivery Reviews 2009, 61, 1193-1202, https://doi.org/10.1016/j.addr.2009.01.007.

99. Park, K. Optimal nanoparticle design for effective transport through the blood-brain barrier. Journal of Controlled Release 2019, 295, https://doi.org/10.1016/j.jconrel.2019.01.024.

100. Inal, S.; Rivnay, J.; Suiu, A.-O.; Malliaras, G.G.; McCulloch, I. Conjugated Polymers in Bioelectronics. Accounts of Chemical Research 2018, 51, 1368-1376, https://doi.org/10.1021/acs.accounts.7b00624.

101. Ahmed, F.; Pakunlu, R.I.; Brannan, A.; Bates, F.; Minko, T.; Discher, D.E. Biodegradable polymersomes loaded with both paclitaxel and doxorubicin permeate and shrink tumors, inducing apoptosis in proportion to accumulated drug. Journal of Controlled Release 2006, 116, 150-158, https://doi.org/10.1016/j.jconrel.2006.07.012.

102. Zindani, D.;Kumar, K. Graphene-based polymeric nano-composites: an introspection into functionalization, processing techniques and biomedical applications. Biointerface research in applied chemistry 2019,9(3),3926-3933, https://doi.org/10.33263/BRIAC93.926933.

103. Chen, W.; Meng, F.; Cheng, R.; Zhong, Z. pH-Sensitive degradable polymersomes for triggered release of anticancer drugs: A comparative study with micelles. Journal of Controlled Release 2010, 142, 40-46, https://doi.org/10.1016/j.jconrel.2009.09.023.

104. Zhang, W.; Zhang, Z.; Zhang, Y. The application of carbon nanotubes in target drug delivery systems for cancer therapies. Nanoscale Research Letters 2011, 6, 1-22, https://doi.org/10.1186/1556-276X-6-555.

105. Patel,S.; Lorincz,K.; Hughes ,R. Monitoring motor fluctuations in patients with Parkinson's disease using wearable sensors. IEEE Trans Inf Technol Biomed 2009, 13, 864-873, https://doi.org/10.1109/TITB.2009.2033471.

106. Moore, S.T.; Yungher, D.A.; Morris, T.R.; Dilda, V.; MacDougall, H.G.; Shine, J.M.; Naismith, S.L.; Lewis, S.J.G. Autonomous identification of freezing of gait in Parkinson's disease from lower-body segmental accelerometry. Journal of NeuroEngineering and Rehabilitation 2013, 10, https://doi.org/10.1186/17430003-10-19.

107. Goubault, E.; Nguyen, H.P.; Bogard, S.; Blanchet, P.J.; Bézard, E.; Vincent, C.; Sarna, J.; Monchi, O.; Duval, C. Remnants of Cardinal Symptoms of Parkinson's Disease, Not Dyskinesia, Are Problematic for Dyskinetic Patients Performing Activities of Daily Living. Frontiers in Neurology 2019, 10, https://doi.org/10.3389/fneur.2019.00256.

108. Ellis, T.; Cavanaugh, J.T.; Earhart, G.M.; Ford, M.P.; Foreman, K.B.; Dibble, L.E. Which measures of physical function and motor impairment best predict quality of life in Parkinson\&\#x2019;s disease? Parkinsonism \& Related Disorders 2011, 17, 693-697, https://doi.org/10.1016/j.parkreldis.2011.07.004.

109. Berganzo, K.; Tijero, B.; González-Eizaguirre, A.; Somme, J.; Lezcano, E.; Gabilondo, I.; Fernandez, M.; Zarranz, J.J.; Gómez-Esteban, J.C. Motor and non-motor symptoms of Parkinson's disease and their impact on quality of life and on different clinical subgroups. Neurología (English Edition) 2016, 31, 585-591, https://doi.org/10.1016/j.nrleng.2014.10.016.

110. Dubey, H.; Goldberg, J.C.; Abtahi, M.; Mahler, L.; Mankodiya, K. Proceedings of the conference on Wireless Health. ACM; 2015. EchoWear: smartwatch technology for voice and speech treatments of patients with Parkinson's disease. 2015.

111. Bayestehtashk, A.; Asgari, M.; Shafran, I.; McNames, J. Fully automated assessment of the severity of Parkinson's disease from speech. Computer Speech \& Language 2015, 29, 172-185, https://doi.org/10.1016/j.csl.2013.12.001. 
112. Maetzler, W.; Liepelt, I.; Berg, D. Progression of Parkinson's disease in the clinical phase: potential markers. The Lancet Neurology 2009, 8, 1158-1171, https://doi.org/10.1016/S1474-4422(09)70291-1.

113. Valappil, R.A.; Black, J.E.; Broderick, M.J. Exploring the electrocardiogram as a potential tool to screen for premotor Parkinson's disease. Mov Disord. 2010, 25, 2296-2303, https://doi.org/10.1002/mds.23348.

114. Hung, S.W.; Adeli, G.M.; Arenovich, T.; Fox, S.H.; Lang, A.E. Patient perception of dyskinesia in Parkinson's disease. Journal of Neurology, Neurosurgery \&amp;amp; Psychiatry 2010, 81, 1112-1115, https://doi.org/10.1136/jnnp.2009.173286.

115. Horak, F.; King, L.; Mancini, M. Role of Body-Worn Movement Monitor Technology for Balance and Gait Rehabilitation. Physical Therapy 2015, 95, 461-470, https://doi.org/10.2522/ptj.20140253.

116. Fisher, J.M.; Hammerla, N.Y.; Rochester, L.; Andras, P.; Walker, R.W. Body-Worn Sensors in Parkinson's Disease: Evaluating Their Acceptability to Patients. Telemedicine and e-Health 2015, 22, 63-69, https://doi.org/10.1089/tmj.2015.0026.

117. Stoker, T.B.; Blair, N.F.; Barker, R.A. Neural grafting for Parkinson's disease: challenges and prospects. Neural Regen Res. 2017, 12, 389-392.

118. Nemeth, C.L.; Fine, A.S.; Fatemi, A. Translational challenges in advancing regenerative therapy for treating neurological disorders using nanotechnology. Advanced Drug Delivery Reviews 2019, 148, 60-67, https://doi.org/10.1016/j.addr.2019.05.003.

119. Ferreira, J.J.; Godinho, C.; Santos, A.T.; Domingos, J.; Abreu, D.; Lobo, R.; Gonçalves, N.; Barra, M.; Larsen, F.; Fagerbakke, Ø.; Akeren, I.; Wangen, H.; Serrano, J.A.; Weber, P.; Thoms, A.; Meckler, S.; Sollinger, S.; van Uem, J.; Hobert, M.A.; Maier, K.S.; Matthew, H.; Isaacs, T.; Duffen, J.; Graessner, H.; Maetzler, W. Quantitative home-based assessment of Parkinson's symptoms: The SENSE-PARK feasibility and usability study. BMC Neurology 2015, 15, https://doi.org/10.1186/s12883-015-0343-z.

120. Fereshtehnejad, S.-M.; Romenets, S.R.; Anang, J.B.M.; Latreille, V.; Gagnon, J.-F.; Postuma, R.B. New Clinical Subtypes of Parkinson Disease and Their Longitudinal Progression: A Prospective Cohort Comparison With Other Phenotypes. JAMA Neurology 2015, 72, 863-873, https://doi.org/10.1001/jamaneurol.2015.0703.

121. Mazilu, S.; Calatroni, A.; Gazit, E.; Mirelman, A.; Hausdorff, J.M.; Troster, G. Prediction of Freezing of Gait in Parkinson's From Physiological Wearables: An Exploratory Study. IEEE J Biomed Health Inform. 2015, 19, 1843-1854.

122. Bachlin, M.; Plotnik, M.; Roggen, D. Wearable assistant for Parkinson's disease patients with the freezing of gait symptom. IEEE Trans Inf Technol Biomed. 2010, 14, 436-446.

123. Rampp, A.; Barth, J.; Schulein, S.; Gassmann, K.G.; Klucken, J.; Eskofier, B.M. Inertial sensor-based stride parameter calculation from gait sequences in geriatric patients. IEEE Trans Biomed Eng. 2015, 62, 10891097.

124. Arora, S.; Venkataraman, V.; Zhan, A.; Donohue, S.; Biglan, K.M.; Dorsey, E.R.; Little, M.A. Detecting and monitoring the symptoms of Parkinson's disease using smartphones: A pilot study. Parkinsonism \& Related Disorders 2015, 21, 650-653, https://doi.org/10.1016/j.parkreldis.2015.02.026.

125. Papapetropoulos, S.; Mitsi, G.; Espay, A.J. Digital Health Revolution: Is it Time for Affordable Remote Monitoring for Parkinson's Disease? Frontiers in Neurology 2015, 6, https://doi.org/10.3389/fneur.2015.00034. 